\title{
Compartilhamento do conhecimento em portais corporativos
}

\author{
Knowledge sharing in corporate portals
}

Eduardo Amadeu Dutra MORESI

Sérgio Peixoto MENDES 2

\section{RESUMO}

No contexto atual da era do conhecimento, um dos maiores desafios enfrentados pelas organizações é o de gerir o conhecimento tácito. Mas como gerenciar o conhecimento que está na cabeça das pessoas? Como motivá-las ao compartilhamento? Para responder a essas questões, o estudo compreendeu um referencial teórico apoiado em gestão do conhecimento, marketing interno e portais corporativos. A pesquisa quantitativa, descritiva e de campo foi realizada no Serviço Federal de Processamento de Dados e contou com a opinião de 55 gestores de conhecimento. $\bigcirc$ resultado foi a identificação dos subsídios necessários para elaboração de programas que permitam mensurar e implementar práticas de reconhecimento e recompensas, visando ampliar o compartilhamento do conhecimento organizacional. Conclui-se que apenas a existência de um portal corporativo não é condição suficiente para garantir o compartilhamento do conhecimento organizacional. É preciso desenvolver práticas motivacionais adequadas, junto ao quadro de colaboradores, para que o conhecimento tácito possa ser compartilhado em portais corporativos.

Palavras-chave: Práticas motivacionais. Gestão do conhecimento. Compartilhamento do conhecimento. Endomarketing.

\section{A B S T R A C T}

In the current context of the knowledge's era, one of the biggest challenges faced by organizations is to manage tacit knowledge. The question is: how to manage inside peoples' minds knowledge? How to motivate them to share it? To answer these questions, this study comprised a theoretical referential about knowledge management, endomarketing and corporate portals. The quantitative, descriptive and field research was held at SERPRO, and holds 55 knowledge managers opinions. The result was the identification of subsidies for the development of programs which enable measuring and implementing recognition practices and rewards in order to increase organizational knowledge sharing. It concluded that the existence of a corporate portal by itself is not enough condition to guarantee enterprise knowledge sharing. It's also necessary to develop motivational practices among employees for tacit knowledge to be shared in corporate portals.

Keywords: Motivational practices. Knowledge management. Knowledge sharing. Endomarketing.

1 Professor Doutor, Universidade Católica de Brasília, Programa de Mestrado em Gestão do Conhecimento e Tecnologia da Informação. QS 07, Lote 01, EPCT, 71996-700, Brasília, DF, Brasil. Correspondência para/Correspondence to: E.A.D. MORESI. E-mail: <moresi@ucb.br>.

2 Serviço Federal de Processamento de Dados. Porto Alegre, RS, Brasil.

Recebido em 5/11/2009 e aceito para publicação em 30/3/2010. 


\section{INTRODUÇÃ O}

Encontrar alternativas que propiciem as condições para gerenciar de maneira inteligente o conhecimento, viabilizando as questões centrais do negócio, é vital para as empresas. A implantação de um programa capaz de gerir o "capital intelectual" pode gerar um diferencial importante no desenvolvimento de novos produtos e serviços (Davenport, 1998). O desejo de atender melhor o cliente, o choque da competição acirrada e a abertura de mercados requerem mudanças significativas não só na maneira de gerir, mas, principalmente, na maneira de incorporar inteligência aos produtos. Este é, portanto, um assunto chave, trata-se de "vantagem competitiva", da própria sobrevivência da empresa nesse ambiente caracterizado pela alta velocidade, instabilidade, desequilíbrio e imprevisibilidade.

Quando as mudanças organizacionais não são planejadas, aumenta a resistência interna, gerando uma série de obstáculos que vão desde a incerteza e falta de disposição até a consciência das fraquezas e falhas propostas pelas novas orientações. Isso tende a aumentar as resistências nos seus aspectos lógico, psicológico e sociológico, que representam por ordem: tempo para ajuste às novas mudanças, medos, falta de confiança e ameaças e, por fim, interesses de grupos que não terão benefícios diretos com a revisão de valores e com as mudanças propriamente ditas (Zabot; Silva, 2002).

O propósito deste trabalho é apresentar o resultado de pesquisa realizada no Serviço Federal de Processamento de Dados (SERPRO) sobre a importância da definição de práticas motivacionais que influenciem o compartilhamento do conhecimento organizacional em portais corporativos. A partir da revisão de literatura, identificou-se a inexistência de estudos focando o endomarketing e o compartilhamento do conhecimento. O resultado prático é a definição de subsídios para a implementação de programas de reconhecimento e recompensas, identificando o que pode motivar as pessoas a utilizarem as ferramentas de compartilhamento de conhecimento em portais corporativos.

\section{GESTÃO DO CONHECIMENTO}

O problema subjacente a este estudo é, em um primeiro momento, a conversão do conhecimento tácito em explícito e, num segundo momento, o problema do compartilhamento do conhecimento no âmbito das organizações. O foco está na gestão do capital intelectual e na criação de um ambiente organizacional adequado para a gestão e o compartilhamento do conhecimento. O Quadro 1 apresenta a relação entre os cinco principais capacitadores do conhecimento e as fases de criação do conhecimento organizacional (Krog etal., 2001).

O estímulo ao compartilhamento, à motivação das pessoas para a cooperação, o comportamento colaborativo e a relação de confiança pertencem aos componentes da cultura organizacional e, por isso mesmo, são requisitos complexos. Esses ativos dependem de fatores individuais e ambientais, mais especificamente da relação entre ambos (Stewart, 1998). Esse conjunto, composto por capital intelectual, capital estrutural e capital de relacionamento possui valor de mercado onde são conhecidos como ativos intangíveis (Sveiby, 2000).

20 Quadro 1. Relacionamento entre capacitadores e as fases da criação do conhecimento.

\begin{tabular}{|c|c|c|c|c|c|}
\hline $\begin{array}{l}\text { Capacitadores de } \\
\text { Conhecimento }\end{array}$ & $\begin{array}{l}\text { Compartilhamento de } \\
\text { Conhecimento Tácito }\end{array}$ & $\begin{array}{l}\text { Criação de } \\
\text { Conceitos }\end{array}$ & $\begin{array}{c}\text { Justificação de } \\
\text { Conceitos }\end{array}$ & $\begin{array}{l}\text { Construção de } \\
\text { Protótipos }\end{array}$ & $\begin{array}{l}\text { Nivelamento de } \\
\text { conhecimento }\end{array}$ \\
\hline Instilar a visão & Fraco & Médio & Forte & Médio & Forte \\
\hline Gerenciar as conversas & Forte & Forte & Forte & Forte & Forte \\
\hline Mobilizar os ativistas & Fraco & Médio & Médio & Médio & Forte \\
\hline Criar o contexto adequado & Médio & Médio & Forte & Médio & Forte \\
\hline $\begin{array}{l}\text { Globalizar o conhecimento } \\
\text { local }\end{array}$ & Fraco & Fraco & Fraco & Fraco & Forte \\
\hline
\end{tabular}

Fonte: Krog et al. (2001). 
Os ativos intangíveis que compõem o capital intelectual de uma empresa podem ser divididos em três categorias (Rezende, 2002): ativos de mercado, que são os bens intangíveis que com ele guardam relação, tais como: carteira de clientes, fidelidade, bancos de dados com informações de fornecedores, canais de distribuição, conjunto de licenças, franquias e, principalmente, aquelas informações relativas aos clientes; ativos de competência individual que compreendem o conhecimento tácito, a expertise, as habilidades pessoais e a capacidade criativa das pessoas e das lideranças do quadro de funcionários da empresa; ativos de estrutura organizacional que englobam o conjunto de ferramentas, de processos, de tecnologias, de metodologias, ou seja, do modus operandi da organização.

Como conhecimento é poder, o seu compartilhamento pode significar a perda de poder. Esse aspecto revela dois tipos de barreiras à criação e ao compartilhamento do conhecimento (Krogh et al., 2001): as individuais - falta de capacidade de acomodação do conhecimento, ameaça à auto-imagem, enclausuramento, falta de confiança mútua e falta de incentivos para o compartilhamento - e as organizacionais - necessidade de linguagem legítima, histórias organizacionais, procedimentos enraizados, paradigmas da empresa e intolerância para com o erro. São barreiras que, apesar de poderem ser estudadas e pesquisadas separadamente, estão fortemente relacionadas.

\section{MOTIVAÇÃO}

A motivação tem sido tema relevante no estudo da administração. Desde o início do século 20, quando as organizações passaram a exercer um papel importante na sociedade e na vida dos homens, o assunto se tornou central. Surgiram diversas escolas e correntes que trataram do aspecto da motivação. Robbins (2002, p.152) define motivação como "o processo responsável pela intensidade, direção e persistência dos esforços de uma pessoa para o alcance de uma determinada meta". Portanto, os três elementos chaves, segundo o conceito acima, são: intensidade, direção e persistência. A intensidade refere-se ao esforço que a pessoa despende, contudo o esforço sem direção não leva a lugar algum. Nesse sentido, é preciso considerar a qualidade do esforço. $\bigcirc$ esforço que deve ser considerado é aquele que pode levar em direção aos objetivos. Já a persistência define por quanto tempo o esforço pode ser mantido. Em suma, os indivíduos motivados se mantêm na realização da tarefa até que os objetivos sejam atingidos.

Quando uma pessoa se coloca em, ou se direciona a um caminho ou um objetivo, ela não necessariamente está motivada a atingir tal objetivo. Os fatores que a levam a caminhar naquela direção podem-lhe ser intrínsecos (internos) ou extrínsecos (externos). Quando são intrínsecos, há motivação; quando são extrínsecos, há apenas movimento ou satisfação (Bueno, 2002).

\section{ENDOMARKETING}

Um novo marketing está surgindo, mais dedicado à criação de valor a partir da inteligência e da oferta de inovação acima da média, dentre outras ofertas, todas enraizadas na cultura organizacional. Denominado de "Marketing do Conhecimento", esse novo marketing tem por finalidade apoiar as estratégias de conhecimento das corporações (Figueiredo, 2003). Ele complementa o marketing tradicional, mas agrega um desafio adicional que é o envolvimento e o comprometimento do pessoal de marketing das organizações com a gestão do conhecimento.

O conceito subjacente ao Marketing do Conhecimento é a arte de descobrir oportunidades, desenvolvê-las e lucrar com elas, o que não permite ao marketing ficar imune à gestão do conhecimento nas organizações (Kotler, 1999). Entretanto o Marketing do Conhecimento precisa contemplar o público interno da organização, transformando-se em endomarketing.

O endomarketing (endo = para dentro) utilizase de elementos do marketing tradicional e os aplica no ambiente interno das organizações (Bekin, 1995). Se os próprios funcionários não comprarem o produto, como vendê-lo ao público externo? Tornar forte esse vínculo entre o funcionário e a empresa para a qual trabalha é fator crítico de sucesso para atender as necessidades dos clientes externos.

Portanto, a estreita relação entre endomarketing e o público interno constitui-se em uma variável determinante para os resultados da organização. Ambos estão inseridos na cultura organizacional e devem ser tratados como assuntos complexos, uma vez 
que envolvem pessoas. Além disso, a justa relação entre marketing e recursos humanos pode gerar lucros ou prejuízos de curtíssimo prazo, principalmente em organizações prestadoras de serviços.

Outra característica importante do endomarketing está relacionada ao conhecimento do negócio da organização por parte de todos os seus funcionários (Bekin, 1995). O endomarketing tem o papel de fazer as pessoas compreenderem, vivenciarem e executarem suas atividades com foco nas necessidades do mercado externo. Nesse aspecto, o atendimento ao cliente externo deixa de ser um esforço apenas do departamento de vendas e passa a ser uma responsabilidade de todos os segmentos da organização.

$\bigcirc$ endomarketing pressupõe dois tipos de processos gerenciais: o gerenciamento de atitudes, que constitui a parte mais importante e predominante do endomarketing e pode viabilizar as vantagens competitivas, despertando nos funcionários novas habilidades requeridas pelo mercado, que exige o seu mapeamento e um sistema eficiente para mensurar os ativos intangíveis; e o gerenciamento da comunicação, que envolve a divulgação ampla daquilo que está acontecendo na empresa, seja em termos de rotina de trabalho, seja em relação aos negócios e campanhas publicitárias.

Em suma, o espírito de cooperação, a confiança e o altruísmo são exemplos de atitudes que podem ser despertadas e trabalhadas a partir de uma política específica ou programa de marketing interno. Obter da força de trabalho as respostas favoráveis às demandas da organização requer motivação, atitudes adequadas e comunicação eficiente. Nesse sentido, um programa de benefícios que propicie o sistema de troca adequado pode atender os requisitos acima e trazer resultados positivos, tanto para a força de trabalho, quanto para a organização como um todo.

\section{FERRAMENTAS TECNOLÓGICAS - PORTAIS CORPORATIVOS}

Não é a tecnologia que garante o sucesso de um projeto de gestão do conhecimento, mas a profunda transformação dos processos, das pessoas e dos meios de produção (Martins, 2001). As ferramentas, no entanto, são imprescindíveis para o processo de compartilhamento. Este trabalho parte do pressuposto de que as empresas possuam um sistema adotado como ponto central de coleta de idéias, nesse caso, os portais corporativos.

Os portais corporativos são ferramentas de integração e comunicação que auxiliam o trabalho dos profissionais de gestão do conhecimento e viabilizam algumas ações de endomarketing. São instrumentos valiosos, também, para os departamentos de recursos humanos. A função principal dos portais, entretanto, é a de facilitar a vida dos próprios empregados. Por meio dos portais corporativos, os empregados podem manifestar-se de diversas formas, seja em comunidades específicas, seja por meio do compartilhamento de experiências, seja por meio dos fóruns, chats e outras ferramentas.

Para os executivos, os portais corporativos são ferramentas importantes para o processo de tomada de decisão, pois viabilizam o acesso rápido a um conjunto de informações, tais como relatórios, atas, currículos e memorandos, tornando mais simples a tarefa de decidir. Segundo Dias (2001), existem diferentes tipos de portais que podem ser classificados segundo seu contexto de utilização em públicos ou corporativos e, em relação às suas funções, em suporte à decisão ou processamento corporativo.

Os requisitos mínimos de um portal corporativo são: facilitar a localização das informações por parte dos usuários eventuais; permitir a classificação e a pesquisa intuitiva; possibilitar o compartilhamento corporativo; prover conectividade universal aos recursos informacionais; viabilizar o acesso dinâmico aos recursos informacionais; permitir roteamento inteligente; viabilizar ferramentas inteligentes de negócios integradas, arquitetura baseada em servidor, serviços distribuídos, definições flexíveis das permissões de acesso, interfaces externas, interfaces programáveis, segurança, fácil administração, customização e personalização (Dias, 2001).

As ferramentas são importantes no processo de compartilhamento, no entanto não se deve esquecer os conselhos propostos por Kotler (1999): nomear uma pessoa experiente e respeitada para ser o gerente de ideias da empresa; encorajar todos os interessados funcionários, fornecedores, distribuidores, revendedores - a enviar suas ideias ao gerente de ideias; estabelecer um programa formal de reconhecimento a fim de recompensar aqueles que, durante o ano, contribuírem com as melhores ideias. 


\section{MÉTODOS}

Considerando a lacuna identificada na revisão de literatura, relativa à inexistência de estudos focando - endomarketing e o compartilhamento do conhecimento, este estudo abordará o seguinte problema: como as ações do marketing de incentivos e do endomarketing, quando utilizadas em portais corporativos, podem transformar-se em práticas de mensuração, de motivação e de reconhecimento para o compartilhamento do conhecimento organizacional?

Este estudo objetivou determinar o perfil de um grupo de pessoas, tendo por base suas características comuns, mensurando: atitudes, opiniões e preferências, relacionadas a práticas motivacionais capazes de serem implantadas para apoiar o compartilhamento do conhecimento organizacional. Esta pesquisa classifica-se, quanto aos fins, numa pesquisa quantitativa descritiva. Os meios utilizados no levantamento dos dados foram a pesquisa bibliográfica, documental e de campo. A pesquisa de campo deu-se por meio da aplicação de questionários com perguntas objetivas.

\section{População}

A população deste estudo foi composta por funcionários da Empresa SERPRO que atuam como representantes de Gestão do Conhecimento Organizacional (GCO) das Unidades da Empresa (superintendências) e por Gestores de Conteúdo da Árvore Serpro de Conhecimento. No total, esses dois perfis somam 69 pessoas, sendo 45 Representantes e 24 Gestores. Desse total, 55 indivíduos retornaram os questionários. $\bigcirc$ primeiro grupo tem atribuições relacionadas ao compartilhamento, nas suas unidades de origem, das políticas, orientações e estratégias vinculadas à gestão do conhecimento organizacional. Os representantes de GCO se reúnem periodicamente para discutirem assuntos relacionados às práticas de compartilhamento de conhecimento e utilização do portal corporativo da empresa. Os membros do segundo grupo possuem como atribuição principal, a manutenção na Árvore Serpro do Conhecimento do tema Computação Distribuída e estão vinculados à Superintendência de Produtos e Serviços de Tecnologia da Informação. São diretamente responsáveis pela validação e análise dos conteúdos compartilhados atualmente no portal relacionado ao tema citado.

A escolha destes dois grupos deve-se, principalmente, ao domínio conceitual nos assuntos vinculados à gestão do conhecimento organizacional, uma vez que foram capacitados no assunto. Além disso, atuam diretamente com os demais colaboradores vinculados às suas superintendências, o que os torna representantes legítimos dos anseios dos demais empregados em relação à gestão do conhecimento na organização.

\section{Perfil dos respondentes}

A população deste estudo é do tipo intencional em função da necessidade do conhecimento prévio dos conceitos vinculados ao GCO. O número de indivíduos respondentes foi de cinquenta e cinco $(n=55)$ no total, sendo representantes de GCO $(n=27)$, gestores de conteúdo $(n=10)$ e outros interessados no assunto (exrepresentantes de GCO, suplentes e ex-gestores de conteúdo) ( $n=18)$ conforme demonstrado na Tabela 1.

\section{Análise dos dados}

Primeiramente foi feito um contato pessoal com os sujeitos da amostra que trabalham na Sede do Serpro em Brasília e, via telefone, com os representantes de GCO e gestores de conteúdo que trabalham fora da sede da empresa. $\bigcirc$ presente estudo também foi apresentado aos representantes de GCO em uma de suas reuniões mensais que ocorrem em Brasília.

O objetivo do contato prévio foi o de apresentar a proposta deste estudo e viabilizar o comprometimento das pessoas com as devoluções dos questionários devidamente respondidos. Os questionários, do tipo fechado e de gradação de opinião, foram encaminhados posteriormente via correio eletrônico aos indivíduos fora da região de Brasília e, pessoalmente, aos representantes e gestores sediados em Brasília.

Os dados coletados foram tabulados e analisados tendo por base a estatística descritiva (média, desvio padrão e tabelas de frequência) e adotou-se como critério de corte os quartis e percentis. Para análise e estatística, utilizou-se o programa MS-Excel. 
Tabela 1. Perfil da população.

\begin{tabular}{|c|c|c|c|c|c|}
\hline Áreas de atuação & $\mathrm{n}$ & Escolaridade & $\mathrm{n}$ & Vinculação com o GCO & $n$ \\
\hline \multirow{5}{*}{$\begin{array}{l}\text { Serviços administrativos } \\
\text { (Gestão Interna) }\end{array}$} & \multirow{5}{*}{24} & $2^{\circ}$ Grau & 2 & \multirow{5}{*}{$\begin{array}{l}\text { Representante } \\
\text { Gestores } \\
\text { Interessados }\end{array}$} & \multirow{5}{*}{$\begin{array}{l}10 \\
7 \\
7\end{array}$} \\
\hline & & Graduação & 4 & & \\
\hline & & Especialização & 16 & & \\
\hline & & Mestrado & 2 & & \\
\hline & & Doutorado & 0 & & \\
\hline \multirow{5}{*}{$\begin{array}{l}\text { Tecnologia da } \\
\text { informação }\end{array}$} & \multirow{5}{*}{22} & $2^{\circ} \mathrm{Grau}$ & 2 & \multirow{5}{*}{$\begin{array}{l}\text { Representante } \\
\text { Gestores } \\
\text { Interessados }\end{array}$} & \multirow{5}{*}{$\begin{array}{l}11 \\
3 \\
8\end{array}$} \\
\hline & & Graduação & 9 & & \\
\hline & & Especialização & 9 & & \\
\hline & & Mestrado & 2 & & \\
\hline & & Doutorado & 0 & & \\
\hline \multirow[t]{5}{*}{ Área de negócios } & 9 & $2^{\circ} \mathrm{Grau}$ & 2 & \multirow{5}{*}{$\begin{array}{l}\text { Representante } \\
\text { Gestores } \\
\text { Interessados }\end{array}$} & \multirow{5}{*}{$\begin{array}{l}6 \\
0 \\
3\end{array}$} \\
\hline & & Graduação & 2 & & \\
\hline & & Especialização & 4 & & \\
\hline & & Mestrado & 1 & & \\
\hline & & Doutorado & 0 & & \\
\hline
\end{tabular}

GCO: gestão do conhecimento organizacional.

\section{Delimitação do estudo}

A pesquisa de campo limitou-se ao âmbito dos usuários do sistema de informação interno do Serpro. Este estudo também não se ocupou com a definição das ferramentas para construção do painel de indicadores e sua respectiva implementação no portal corporativo. Os resultados foram apresentados ao Serpro como proposta para o aumento do índice de colaboração e publicação de novos conteúdos no portal; sua efetiva aprovação junto à diretoria e posterior implantação não fazem parte do escopo deste trabalho.

A população ficou restrita aos representantes de GCO, gestores de conteúdo e outros interessados no assunto (ex-representantes e ex-conteudistas), todos usuários internos do Serpro.

Não fez parte do escopo de estudo a definição das ferramentas para construção do painel de indicadores e sua respectiva implementação no portal corporativo.

presente estudo foi apresentado como proposta e os seus resultados de curto prazo não dependem da implementação efetiva do programa.

\section{RESULTADOSE DISCUSSÃO}

A importância dos registros confiáveis, imediatos e permanentes aparecerem na história da administração já em 1912, com Harrington Emerson (Lodi, 1974). Obviamente, o que Emerson tinha em mente era uma estatística voltada para o controle de custos com matéria-prima e mão-de-obra. Os registros confiáveis faziam parte dos seus 12 princípios de eficiência na arte de administrar. Assim, medir, mensurar e controlar fazem parte do processo administrativo desde os primórdios da Administração. Atualmente mudou-se apenas "o que" deve ser medido.

Neste estudo, os indicadores adicionam ao processo de gestão do conhecimento organizacional um novo conjunto de estruturas, processos e medidas que avaliam toda a base de recursos a partir das quais a organização gera valor aos seus produtos e serviços.

As melhores medições combinam basicamente duas ideias: introdução de indicadores-chave que podem ajudar a compreender o rumo da gestão do conhecimento organizacional e indicadores que tenham relação direta com os resultados. Isto torna importantes os indicadores vinculados à gestão do conhecimento, principalmente no contexto atual da "Era do Conhecimento".

Pesquisa recente realizada por Michelman (2004) aponta para a existência de "filtros" que controlam quais os dados que nos interessam realmente. É o interesse que direciona as informações em nossas mentes, diz o autor. As lideranças responsáveis pelo processo de tomada de decisão devem adotar medidas 
para se resguardarem do isolamento no momento de decidirem: isso evita que algumas informações sejam, literalmente, "despachadas para os recantos escuros da mente". Os indicadores de GCO não podem estar expostos ao risco de serem analisados unicamente pela alta direção da empresa. Os resultados deste estudo apontam igualmente nesta direção.

Dos 55 respondentes, 50 concordam que os indicadores são importantes para todos os colaboradores e lideranças. Por meio dos indicadores, pode-se identificar a importância do valor dos ativos intangíveis para o negócio da empresa, ou seja: o valor do capital intelectual. Este estudo revela que os indicadores de GCO são importantes não apenas para as lideranças. Dos 55 respondentes, 46 não concordam que os indicadores de GCO são importantes apenas para as lideranças da organização. Há concordância também em relação à facilidade que os indicadores de GCO proporcionam para a tomada de decisões estratégicas para a organização.

Dos 55 respondentes, 41 concordam que os indicadores de GCO são importantes e podem influenciar nos resultados da empresa. Já em relação ao comprometimento das pessoas com o compartilhamento do conhecimento, os indicadores de GCO, por si só, nada podem e perdem sua importância segundo a opinião de 21 respondentes. Entretanto, os dados revelam que o marketing interno, no seu segmento de comunicação, pode ser utilizado como ferramenta de contribuição para aumentar a cultura de compartilhamento. O endomarketing, ao tornar transparentes os resultados relacionados à gestão do conhecimento organizacional para todos na empresa, aumenta a credibilidade e os índices de confiança entre a força de trabalho e a alta direção.

É apresentado uma proposta de um conjunto de indicadores identificados, por este estudo, e validados pelos respondentes (Tabela 2 ), que foram considerados como os mais adequados para comporem o painel de indicadores, tornando capaz a identificação de dados objetivos (numéricos) que viabilizem a aplicação de práticas motivacionais de reconhecimento e recompensas. Os indicadores aparecem com a pontuação que lhe foi atribuída pelos 55 respondentes desta pesquisa. Fatores de maximização do compartilha-
mento do conhecimento organizacional

Albrecht (2004) alerta para o fato de que não basta reunir pessoas inteligentes na empresa para buscar a inteligência organizacional, é preciso evitar a estupidez coletiva. Nesse sentido, é importante mobilizar todo o potencial intelectual disponível e concentrar tal capacidade na realização da missão da organização. Essa mobilização passa, necessariamente, pela motivação da força de trabalho e, especialmente, pela eliminação dos desperdícios da capacidade mental das pessoas.

Os resultados apontados pelo presente estudo, relativos aos fatores que podem maximizar o compartilhamento no âmbito individual, vão na direção da realização intrínseca e da oportunidade de crescimento. Esses dois fatores, segundo os respondentes, podem aumentar a motivação e o entusiasmo para o compartilhamento do conhecimento, melhorando, dessa maneira, os índices de inteligência na organização. A Tabela 3 apresenta uma síntese desses fatores e revela que 43 respondentes indicam a realização intrínseca, oportunidade de crescimento e o entusiasmo pela atividade que exercem na organização como fatores importantes para a maximização do compartilhamento do conhecimento.

\section{Identificação dos fatores que influenciam o compartilhamento do conhecimento}

Segundo Senge (1999), nenhuma mudança significativa ocorrerá numa organização se não for acionada pela alta administração e nenhuma mudança ocorrerá se a alta administração não "comprar a ideia". E, complementa, não há sentido em prosseguir a não ser que o presidente esteja a bordo. Os resultados apontados por este estudo confirmam a tese de Senge. A eficácia da liderança e o apoio prático dos líderes e responsáveis pelos processos e funções relacionados ao conhecimento a ser compartilhado foram apontados como os principais fatores de influência no compartilhamento do conhecimento. Alerta Senge, no entanto, que nenhuma mudança significativa pode ocorrer se for dirigida apenas de cima. Fica evidente que o poder da alta liderança é importante, mas possui suas limitações. É importante consultar e ouvir a força de trabalho quando da implantação de mudanças, principalmente daquelas que envolvam aspectos profundos.

Outro aspecto significativo está relacionado à importância do apoio prático aos processos de compartilhamento. Assim, mesmo havendo vontade e interesse em compartilhar, é preciso que haja também 
condições e orientações técnicas para que o compartilhamento realmente ocorra. A Tabela 4 apresenta os principais fatores que implicam mudanças organizacionais significativas para que se possa influenciar o compartilhamento do conhecimento.

Tabela 2. Painel de indicadores.

\begin{tabular}{clc}
\hline Ranking & \multicolumn{1}{c}{ Indicadores } & Pontuação \\
\hline 1 & Eficácia do compartilhamento de informações entre os departamentos e superintendências & 260 \\
2 & $\begin{array}{l}\text { Índice de comprometimento da alta administração e demais lideranças, relacionado ao } \\
\text { compartilhamento do conhecimento organizacional }\end{array}$ & 248 \\
3 & $\quad$ Índice de atualização de conhecimentos institucionais na árvore de conhecimento & 242 \\
4 & Nível de acesso às informações, por parte dos interessados, aos conhecimentos essenciais ao & 239 \\
& negócio da organização & 238 \\
5 & Índice de conhecimentos individual atualizado no Sistema de Currículos & 235 \\
6 & Índice de assuntos atualizados na árvore de conhecimento & 234 \\
7 & Índice de utilização do banco de conhecimentos & 213 \\
8 & Índice de utilização das contribuições individuais no Portal Corporativo & 211 \\
10 & Índice de participação dos empregados em pesquisas no Portal Corporativo de participação dos empregados em cursos de Ensino a Distância & 210 \\
11 & Nível de abrangência da divulgação dos indicadores de aprendizado e crescimento & 206 \\
12 & Porcentagem de empregados que apresentaram sugestões de melhoria para do portal & 206 \\
13 & Índice de utilização das Comunidades de Prática & 205 \\
14 & Porcentagem da força de trabalho com direito a receber incentivos por suas contribuições no & 204 \\
15 & Portal Corporativo & 197 \\
16 & Quantidade de contribuições por indivíduo no Portal Corporativo & 191 \\
\hline
\end{tabular}

Obs. A média da pontuação foi de 221 pontos.

Tabela 3. Fatores de maximização do compartilhamento do conhecimento.

\begin{tabular}{lc}
\hline Fatores & Frequência \\
\hline Relação intrínseca e oportunidade de crescimento & 12 \\
Realização e entusiasmo pelo trabalho e recompensas monetárias & 12 \\
Realização e entusiasmo pelo trabalho e conhecimento da organização/produtos & 11 \\
Realização e entusiasmo pelo trabalho e ferramentas amigáveis & 8 \\
Oportunidade de crescimento e recompensas não monetárias & 4 \\
Oportunidade de crescimento e conhecimento da organização/produto & 4 \\
Oportunidade de crescimento e ferramentas amigáveis & 1 \\
Recompensas não monetárias e conhecimento da organização/produto & 1 \\
Recompensas não monetárias e ferramentas amigáveis & 1 \\
Conhecimento da organização e ferramentas amigáveis & 1 \\
\hline
\end{tabular}

Tabela 4. Fatores que influenciam o compartilhamento do conhecimento.

\begin{tabular}{lc}
\hline Fatores & Frequência \\
\hline Eficácia da liderança e apoio prático & 13 \\
Eficácia da liderança e trabalho em grupo & 10 \\
Eficácia da liderança e aprendizagem e desenvolvimento & 7 \\
Eficácia da liderança e recompensas monetárias & 7 \\
Apoio prático e trabalho em grupo & 6 \\
Apoio prático e aprendizagem e desenvolvimento & 4 \\
Apoio prático e recompensas monetárias & 3 \\
Trabalho em grupo e aprendizagem e desenvolvimento & 3 \\
Trabalho em grupo e recompensas monetárias & 1 \\
Aprendizagem e desenvolvimento e recompensas monetárias & 1 \\
\hline
\end{tabular}




\section{PRINCIPAIS OBSTÁCULOS INDIVIDUAIS AO COMPARTILHAMENTO}

Os principais obstáculos apresentados pelos respondentes estão relacionados à falta de tempo para o compartilhamento e ao interesse das pessoas no conhecimento que se pode compartilhar. Quem tem interesse e motivação para compartilhar não conhece o tipo de conhecimento a que as outras pessoas querem ter acesso. Nesse sentido, criar o "momento do compartilhamento" e ter identificado os tipos de conhecimento que realmente interessam às pessoas e à organização é fator crítico de sucesso para a superação dos dois obstáculos apontados pelo estudo. Dos 55 respondentes, 44 alegam a falta de tempo como um dos principais obstáculos ao compartilhamento (Tabela 5). Nesse sentido, a criação de um "momento do compartilhamento" justifica-se e é fator de sucesso para estimular o compartilhamento do conhecimento organizacional.

\section{O ENDOMARKETING E OS OBSTÁCULOS AO COMPARTILHAMENTO}

Em relação aos obstáculos ao compartilhamento do conhecimento, a análise da Tabela 5 aponta outros aspectos que dificultam o compartilhamento do conhecimento e criam uma série de obstáculos que precisam ser superados pelas organizações. A ausência de benefícios pessoais aparece como um forte obstáculo ao compartilhamento. O medo de perder o poder de barganha junto à organização já havia sido apontado como um dos maiores obstáculos ao compartilhamento por diversos autores (Davenport; Prusak, 1998; Krog et al., 2001) que atribuem à falta de confiança e à perda da auto-imagem a causa do enclausuramento do conhecimento por medo de perda do poder. O terceiro obstáculo está relacionado à ausência de benefícios. $\mathrm{A}$ pergunta que surge é: por que gerar mais trabalho para mim mesmo, compartilhando conhecimento, se não há um retorno financeiro para tal atitude? Esse tipo de obstáculo indica a necessidade de fortalecimento das práticas de reconhecimento e recompensas com o objetivo de restabelecer, inclusive, a cultura de confiança. É um desafio que o endomarketing, como ferramenta de apoio, precisa superar.

Bukowitz e WIlliams (2002) defendem a tese de que o marketing e o endomarketing podem fortalecer e restabelecer a relação de confiança entre a organização e sua força de trabalho. A proposta dos autores aponta para a necessidade de insuflar a transparência de informações no âmbito organizacional. A estratégia da organização necessita ser comunicada a todos os empregados. É preciso deixar claros os benefícios do compartilhamento do conhecimento em todos os níveis da organização. A Tabela 6 apresenta os resultados de questões relativas ao endomarketing e aos obstáculos ao compartilhamento do conhecimento.

Tabela 5. Principais obstáculos ao compartilhamento do conhecimento.

\begin{tabular}{lc}
\hline Obstáculos & Frequência \\
\hline Falta de tempo e interesse das outras pessoas & 27 \\
Falta de tempo e ajuda para organizar & 9 \\
Falta de tempo e diferença da contribuição & 8 \\
Incentivo do chefe e interesse das pessoas & 4 \\
Incentivo do chefe e diferença da contribuição & 3 \\
Interesse das outras pessoas e ajuda para organizar & 2 \\
Interesse das outras pessoas e diferença da contribuição & 1 \\
Ajuda para organizar e diferença da contribuição & 1 \\
\hline
\end{tabular}

Tabela 6. Resultados sobre as questões de endomarketing.

\begin{tabular}{|c|c|c|}
\hline Questões & Concordam & Discordam \\
\hline $\begin{array}{l}\text { O marketing interno busca revitalizar a idéia de que os indivíduos e a organização são } \\
\text { interdependentes no alcance de seus objetivos. Essa estratégia de marketing pode melhorar } \\
\text { os índices de compartilhamento de conhecimento organizacional }\end{array}$ & 47 & 8 \\
\hline $\begin{array}{l}\text { Algumas pessoas não compartilham o conhecimento porque não têm benefícios pessoais } \\
\text { ao fazê-lo }\end{array}$ & 44 & 9 \\
\hline $\begin{array}{l}\text { Algumas pessoas não compartilham o conhecimento porque, ao fazê-lo, enfraquecem o } \\
\text { seu poder de barganha junto à empresa }\end{array}$ & 32 & 20 \\
\hline $\begin{array}{l}\text { Algumas pessoas não compartilham conhecimento, porque ao fazê-lo, geram mais encargos } \\
\text { para si mesmos }\end{array}$ & & \\
\hline
\end{tabular}


O marketing interno busca revitalizar a ideia de que os indivíduos e a organização são interdependentes no alcance de seus objetivos e essa estratégia pode melhorar os índices de compartilhamento de conhecimento organizacional. O endomarketing, como estratégia de comunicação e transparência das informações, atua diretamente na formação e recuperação de um clima de confiança, o que confirma a hipótese de que as ações de comunicação interna contribuem para uma cultura de compartilhamento de conhecimento.

\section{CRIAÇÃO DE AMBIENTE AO COMPARTILHAMENTO DO CONHECIMENTO}

Implementar e desenvolver a cultura da colaboração ou a cultura da competitividade dependem da criação do contexto e da abordagem da organização em relação ao tipo de prática motivacional que vier a adotar. $O$ indicado, pela literatura, é estimular a cooperação entre a força de trabalho da empresa e não a competitividade. Nesse sentido, as práticas motivacionais precisam ser rigorosamente escolhidas para não estimular a competição interna. Este estudo objetivou identificar as práticas mais adequadas ao perfil que a organização quer ter em relação aos processos de compartilhamento do conhecimento.

A definição de um conjunto de valores culturais a serem buscados pela força de trabalho não se constitui objeto deste estudo, mas, devido à importância do assunto, aparece como indicativo para trabalhos futuros no final deste relatório. Segundo Miller (2002), alterar o comportamento e a cultura corporativa requer fortes ajustes nas atitudes e pode levar de três a sete anos de trabalho pesado.

Neste estudo, identificou-se que a criação do contexto adequado passa, necessariamente, pelo patrocínio e pelo exemplo das lideranças, que são fatores importantes no processo de compartilhamento de conhecimento na organização. Dos 55 respondentes, 50 concordam que o exemplo deve vir das lideranças, juntamente com o apoio e o patrocínio para a criação de um ambiente de compartilhamento adequado.

Além disso, um ambiente favorável ao compartilhamento do conhecimento pode estimular a produtividade e melhorar os processos operacionais. Os resultados apontam que dos 55 respondentes, 51 também concordam que o compartilhamento do conhecimento pode reduzir custos para a organização ao melhorar os processos, as condições físicas e estimular a produtividade. Assim, para utilizar a motivação de forma eficiente no ambiente organizacional, cinco fatores são fundamentais: direção de liderança, estilo de gerenciamento, ambiente físico, grupo de trabalho, oportunidades para aprender e desenvolver a carreira, além das recompensas e reconhecimento.

\section{MODELO DE MAITLAND}

Para que a inteligência organizacional, constituída pelo conjunto de saberes da força de trabalho da organização, tenha êxito, é preciso que a informação passe daquele que a detém para o profissional que necessita dela. Ter consciência do valor que os dados e as informações que possuímos possam ter para o colega de trabalho é fator crítico de sucesso em qualquer processo de compartilhamento. Do total de respondentes, 55 concordam com a afirmação acima.

Ainda em relação às formas de incentivo, o estudo constatou que, 49 respondentes concordam que as metas de desempenho vinculadas ao compartilhamento do conhecimento organizacional podem melhorar a quantidade e a qualidade das contribuições no portal corporativo.

Trinta e seis respondentes concordam que o compartilhamento do conhecimento para acontecer depende de incentivos externos (motivação extrínseca) 15 não concordam e 4 são indiferentes. O conceito de motivação extrínseca é compreendido como um conjunto de práticas de incentivos e premiações concedidas pela organização, tais como: reconhecimento público, condecorações, adicionais salariais, reconhecimento social, recompensas relacionadas ao trabalho e outras formas de incentivos.

Segundo o modelo de Maitland (2000), os reforços de comportamentos são de quatro tipos: incentivo de cunho social; incentivo de cunho simbólico; incentivo de cunho relacionado ao trabalho e incentivo de cunho financeiro.

A Tabela 7 mostra, em percentuais, que 0 incentivo de cunho financeiro é o preferido dos 55 respondentes, confirmando a hipótese de que as práticas motivacionais extrínsecas favorecem o compartilhamento do conhecimento organizacional. 
Tabela 7. Percentuais de aprovação por tipo de incentivo.

\begin{tabular}{lc}
\hline Tipos de Incentivos & Aprovação (\%) \\
\hline Incentivo de cunho financeiro & 74,5 \\
Incentivo de cunho relacionado & 72,7 \\
ao trabalho & \\
Incentivo de cunho social & 52,7 \\
Incentivos de cunho simbólico & 41,8 \\
\hline
\end{tabular}

\section{Incentivo de cunho social}

Trata-se de reconhecimento público transmitido ao empregado por ocasião de uma realização. Os resultados deste estudo demonstram que 29 respondentes concordam e 22 discordam que os incentivos de cunho social, tais como reconhecimento público, agradecimentos formais e outros, são mais importantes do que reconhecimento e recompensas financeiras, de cunho simbólico, de cunho relacionado ao trabalho.

\section{Incentivo de cunho simbólico}

Trata-se de algo que é dado ao empregado, significando reconhecimento por uma meta atingida ou uma realização importante. Os incentivos de cunho simbólico, tais como pequenas premiações, troféus e outros, são menos importantes do que as recompensas financeiras e os incentivos de cunho social e outros relacionados ao trabalho. Dos 55 respondentes, 23 concordam e 25 discordam que esse tipo de prática motivacional possa favorecer e incentivar o compartilhamento do conhecimento.

\section{Incentivo de cunho relacionado ao trabalho}

Trata-se de forma de reconhecimento diretamente ligada ao trabalho do empregado. Os Incentivos de cunho relacionado ao trabalho, tais como: participação em workshop, participação em projetos inovadores, seminários e congressos são fatores motivantes mais importantes do que os relacionados nos dois itens acima. Nesta pesquisa, 40 respondentes concordam e 14 discordam desta prática de incentivos.

\section{Incentivos de cunho financeiro}

O incentivo para a eficiência constituía o $12^{\circ}$ princípio estabelecido por Emerson, em 1912 (Lodi,
1974). O ponto de partida desse princípio é de que o trabalhador age sempre de acordo com os interesses pelo ganho material, o qual o leva a produzir individualmente o máximo possível. O 12 p princípio de Emerson levava em consideração a visão que Taylor tinha dos trabalhadores da sua época, no ano de 1912, em que a indolência era um comportamento natural do trabalhador e precisava ser eliminada (Lodi, 1974).

Trabalhar exclusivamente pelo ganho material constitui-se numa visão simplificada do ser humano. O conceito de homo economicus, do início do século passado, não leva em conta outros fatores motivacionais, mas, apesar de simplificar a personalidade humana, ainda constitui um fator motivacional importante, mesmo nas práticas motivacionais encontradas mais recentemente nas organizações.

Neste estudo os incentivos de cunho financeiro, tais como bônus e adicionais de salários, aparece como o mais importante dos fatores motivacionais. Dos 55 respondentes, 41 concordam que os incentivos financeiros podem melhorar os índices de compartilhamento e apenas 11 respondentes discordam dessa prática.

Os números acima sustentam, senão completamente, pelo menos em parte, a Teoria das Necessidades de Maslow (1987) na qual a preocupação com as necessidades básicas (que o dinheiro pode proporcionar) aparece como prioritária, na base da pirâmide.

\section{OUTROS ASPECTOS IDENTIFICADOS PELA PESQUISA}

As respostas vinculadas às ferramentas de apoio ao compartilhamento, tais como o portal corporativo e os sistemas gestores de conteúdo, aparecem com inexpressiva votação como fatores que podem maximizar o compartilhamento do conhecimento. Esse fato pode confirmar a altíssima satisfação dos respondentes explicitadas nas questões relacionadas à tecnologia, que é apresentada na Tabela 8. Mas, pode-se concluir também a partir dessas evidências, que as ferramentas, quando disponíveis e de fácil acesso, não são sequer percebidas como mecanismos essenciais ao processo de compartilhamento. Isso confirma a tese de diversos autores de que as ferramentas funcionam muito bem como meio, mas não têm influência direta como prática motivacional ao processo de compartilhamento de conhecimento. É apenas a ponta do iceberg. 
Sobre as práticas motivacionais, existe uma dissonância entre os fatores motivantes que são: realização intrínseca, oportunidade de desenvolvimento e realização intrínseca, entusiasmo pelo trabalho e recompensas não monetárias, com 24 votos dos 55 possíveis em relação aos resultados que aparecem na Tabela 4, vinculados às práticas de incentivo, em que incentivo de cunho financeiro recebeu o maior grau de concordância, com um percentual de 74,5\%. A dissonância só não é maior porque os incentivos de cunho relacionado ao trabalho aparecem na segunda posição entre os mais votados pelos respondentes com 72,7 \%.

A tecnologia exerce um papel fundamental no compartilhamento do conhecimento organizacional e no direcionamento do fluxo do conhecimento para um ponto central, onde ele possa ser coletado, analisado e avaliado. Os portais corporativos enquanto ferramentas adotadas como ponto de coleta do conhecimento e sua importância como ferramenta de integração para o trabalho diário, facilidades de acesso e disponibilidade, formulários eletrônicos de contribuição (SGC) e capacitação do usuário para uso da tecnologia, foram elementos verificados e confirmados neste estudo.

Os resultados aparecem na Tabela 8 e apontam altos índices de concordância por parte dos 55 respondentes. Apenas 10, considerando as quatro questões apresentadas, foram indiferentes em relação às ferramentas apresentadas.
Sobre as fontes de aquisição do conhecimento, este estudo identificou que os programas motivacionais, voltados para o compartilhamento do conhecimento, melhoram os índices de aproveitamento e reutilização do conhecimento explícito já existente na organização. Dos 55 respondentes, 48 concordam que as práticas motivacionais também podem contribuir para a aquisição de novos conhecimentos. A respeito desse aspecto, é importante estar atento ao alerta proposto por Martens (2004) no qual, para evitar que as novas ideias fracassem, o melhor caminho é sempre testá-las de maneira correta. $O$ autor aponta oito passos fundamentais para que os testes sejam bem sucedidos, são eles: avaliar o melhor momento; fazer testes cedo e com frequência; procurar fontes de testes capazes de contribuir de forma única; estar aberto para o inesperado; manter uma distância emocional segura; não esquecer de testar o contexto; procurar usuários leigos e, por fim, se tudo falhar, confiar no instinto. Somente superando essas etapas uma idéia nova está pronta para se transformar em produto.

Sobre as novas fontes de conhecimento, este estudo constatou que, dos 55 respondentes, 48 apontam que fontes externas, tais como agência de notícias, periódicos, congressos, feiras são, igualmente, fontes importantes para a aquisição de novos conhecimentos. A Tabela 9 sintetiza os aspectos relacionados à aquisição de novos conhecimentos.

Tabela 8. Resultados sobre as questões vinculadas a tecnologia.

\begin{tabular}{|c|c|c|}
\hline \multirow{2}{*}{ Tecnologia } & \multicolumn{2}{|c|}{ Respondentes } \\
\hline & Concordam & Discordam \\
\hline $\begin{array}{l}\text { Você faz parte de um grupo de profissionais que compõe a rede de transferência } \\
\text { de informações na organização. Nesse sentido, o portal corporativo, como } \\
\text { ferramenta de integração e compartilhamento de conhecimento, é o instrumento } \\
\text { mais importante para o seu trabalho diário }\end{array}$ & 46 & 6 \\
\hline $\begin{array}{l}\text { As facilidades de acesso ao portal (Internet e Intranet) têm influência direta na } \\
\text { sua utilização como ferramenta de compartilhamento do conhecimento } \\
\text { organizacional }\end{array}$ & 54 & 1 \\
\hline $\begin{array}{l}\text { Os Sistemas Gestores de Conteúdo (SGC), também conhecidos como } \\
\text { formulários eletrônicos de contribuição, são ferramentas- chave no processo de } \\
\text { compartilhamento do conhecimento organizacional }\end{array}$ & 49 & 1 \\
\hline $\begin{array}{l}\text { O treinamento e o aculturamento dos colaboradores no uso da tecnologia da } \\
\text { informação têm influência direta no compartilhamento do conhecimento } \\
\text { organizacional }\end{array}$ & 53 & 0 \\
\hline
\end{tabular}

Nota: a diferença para " $\mathrm{n}$ " 55 pertence aos respondentes indiferentes. 
Tabela 9. Resultados relacionados à aquisição de novos conhecimentos.

\begin{tabular}{lcc}
\hline Questões & Concordam & Discordam \\
\hline A principal fonte de aquisição de novos conhecimentos é a própria organização & 38 & 13 \\
$\begin{array}{l}\text { Outras fontes de conhecimento, tais como agência de notícias, periódicos, congressos e } \\
\text { feiras são fontes de aquisição de novos conhecimentos tão importantes quanto as fontes } \\
\text { internas }\end{array}$ & 48 & 7 \\
$\begin{array}{l}\text { Os programas motivacionais, voltados para o compartilhamento do conhecimento, melhoram } \\
\text { os índices de aproveitamento do conhecimento já existente na organização }\end{array}$ & 48 & 4 \\
$\begin{array}{l}\text { O principal benefício do compartilhamento do conhecimento é agilizar o processo de tomada } \\
\text { de decisão }\end{array}$ & 38 \\
\hline
\end{tabular}

\section{CONSIDERAÇÕES FINAIS}

A pesquisa comprova que as questões comportamentais, culturais e de comunicação interna são fatores críticos de sucesso para que a implantação da gestão do conhecimento organizacional seja eficiente e eficaz. A conversão do conhecimento, de tácito para explícito, pode significar um diferencial competitivo, mas, é preciso levar em consideração que é o valor daquilo que se compartilha e não o volume que pode gerar a força motriz para os processos de inteligência da organização.

A inteligência está com as pessoas e o compartilhamento depende da sua motivação para ocorrer. Nesse aspecto, as práticas motivacionais podem auxiliar desde que estejam respaldadas no exemplo e no envolvimento das lideranças e da alta direção da organização. Além disso, as práticas motivacionais precisam estar adequadas ao perfil das pessoas e serem compatíveis com a cultura da organização.

Nesse sentido, esta pesquisa constatou e, de certa forma, validou o que frequentemente se encontra como alerta na literatura vinculada ao assunto da gestão do conhecimento organizacional. Para a gestão apresentar resultados, não basta formular o melhor plano e adquirir a melhor tecnologia. É preciso, antes de tudo, compreender profundamente o lado humano e criar um a linhamento entre cultura, comportamento e valores na empresa e fortalecer práticas sistematizadas que possam alavancar a motivação e estimular o engajamento das pessoas.

Constatou-se, também, a importância do exemplo e do apoio das chefias e da alta administração. Além disso, compete às chefias providenciar para que todas as orientações operacionais sejam repassadas, viabilizando o manuseio, de forma eficiente, dos sistemas que viabilizam o compartilhamento do conhecimento na organização. $\bigcirc$ exemplo deve vir de cima e trata-se de um grande elemento motivador. Portanto, para a força de trabalho ter confiança, os chefes devem manter a coerência entre o discurso e a prática.

A implementação da gestão do conhecimento é uma mudança radical e deve chegar ao nível de todos os empregados. Nesse aspecto, o processo de comunicação interna e as técnicas do endomarketing tornam-se imprescindíveis para dar a visibilidade necessária, as estratégias, diretrizes, planos, conhecimento do negócio, metas e, principalmente, alinhar os interesses dos empregados e da empresa. Validar a contribuição de todos é fundamental para encontrar o ponto de benefício mútuo e a reciprocidade entre a força de trabalho e a organização.

A pesquisa também constatou que a tese do homo economicus continua válida para explicar a tendência das pessoas em optarem por recompensas e reconhecimento de caráter financeiro, conforme demonstrado no Tabela 7.

Confirmou-se também que os indicadores de GC podem facilitar a implementação de incentivos, dandoIhes caráter objetivo. As técnicas do marketing de incentivos, efetivamente, precisam estar apoiadas em dados concretos, objetivos, para não terem sua validade questionada. Nesse sentido, o painel de indicadores implantado no portal corporativo, pode, além de fornecer transparência e dar visibilidade aos dados, garantir a sustentabilidade e a credibilidade dos programas motivacionais de reconhecimento e recompensas.

Como trabalho futuro, recomenda-se a implementação dos indicadores, conforme identificados nesta pesquisa, e a publicação de um painel de indicadores, no portal corporativo, com o objetivo de 
avaliar os resultados relacionados aos aspectos motivacionais, aos índices das contribuições, ao envolvimento das chefias e a outros apontamentos feitos por este estudo. Essa análise permitirá identificar a necessidade ou não da geração de outros indicadores para mensurar o compartilhamento e a motivação das pessoas.

Os dados indicativos do painel de indicadores podem viabilizar estudos na área de implementação de programas motivacionais, tais como: por acúmulo de pontuação, nos moldes dos programas de milhagem aplicados pelas empresas aéreas, com o objetivo de manter a fidelidade dos empregados em relação à usabilidade do portal corporativo e ao compartilhamento de conhecimento. Os dados objetivos podem contemplar o reconhecimento e as recompensas do tipo financeiras em função da sua transparência.

Estudos futuros necessitam definir critérios para identificar o tipo de conhecimento útil para a organiza- ção apoiado no alinhamento estratégico e na obtenção da vantagem competitiva.

Como trabalho futuro, identifica-se a necessidade de definição de critérios de proteção e segurança da informação que seja vital para o negócio da organização. Também é importante definir um conjunto de critérios de compartilhamento de conteúdo que torne o processo ético e legal, observando os requisitos de direitos autorais vinculados à produção do conhecimento. Evitar a apropriação indébita por parte da organização é uma questão legal que precisa ser observada.

Trabalhos futuros precisam definir um conjunto de competências profissionais indispensáveis que possam contribuir para a construção do processo de inteligência organizacional, implementando as sugestões deste estudo e aplicando ciclo de melhoria aos processos atuais.

\section{REFERÊNCIAS}

ALBRECHT, K. Um modelo de inteligência organizacional. HSM Management, n.44, p.30-4, 2004.

BEKIN, S.F. Conversando sobre endomarketing. São Paulo: Makron Books, 1995.

BUENO, M. As teorias de motivação humana e sua contribuição para a empresa humanizada: um tributo a Abraham Maslow. Revista do Centro de Ensino Superior de Catalão - CESUC, v. 4n.6, 2002. Disponível em: <http://www.cesuc.br/revista/ed-1/ ASTEORIASDEMOTIVACAOHUMANA. pdf > . Acesso em: 20 out. 2004.

BUKOWITZ, W. R.; WILLIAMS, R.L. Manual de gestão do conhecimento: ferramentas e técnicas que criam valor para a empresa. Porto Alegre: Bookman, 2002.

DAVENPORT, T.H. Ecologia da informação: por que só a tecnologia não basta para o sucesso na era da informação. São Paulo: Futura, 1998.

DAVENPORT, T.H.; PRUSAK, L. Working knowledge: how organizations manage what they know. Boston: Harvard Business School, 1998.

DIAS, C.A. Portal corporativo: conceitos e características. Ciência da Informação, v.30, n. 1, p.50-60, 2001

FIGUEIREDO, S.P. O marketing do conhecimento. Intermanegers, 2003. Disponível em: <http:// www.intermanagers.com.br>. Acesso em: 26 ago. 2003.

KOTLER, P. Marketing para o século XXI. São Paulo: Futura, 1999.

KROG, G.; ICHIJO, K.; NONAKA, I. Facilitando a criação do conhecimento: reinventando a empresa com o poder da inovação contínua. Rio de Janeiro: Campus, 2001.

LODI, J. B. História da administração. 3. ed. São Paulo: Pioneira, 1974.

MAITLAND, I. Como motivar pessoas. São Paulo: Nobel, 2000.

MARTENS, C. A distancia entre as idéias e os produtos. HSM Mangement Update 12, n.44, p. 1-4, 2004.

MARTINS, M. Extraia dividendos do capital intelectual de sua empresa. Disponível em: <http://www.banasqualidade.com.br>. Acesso em: 1 abr. 2001

MASLOW, A. Motivação e personalidade: teoria da hierarquia das necessidades. New York: Harper Row, 1987.

MICHELMAN, P. O que os líderes se permitem saber. HSM Management Update 12, n.44, p. 1-4, 2004.

MILLER, J.P. O milênio da inteligência competitiva. Porto Alegre: Bookmann, 2002.

REZENDE, I. Informação para negócios: os novos agentes do conhecimento e a gestão do capital intelectual. Ciência da Informação, v.31, n. 1, p.75-83, 2002.

ROBBINS, S.P. Comportamento organizacional. São Paulo: Prentice Hall, 2002.

SENGE, P. A dança das mudanças: os desafios de manter o crescimento e o sucesso em organizações que aprendem. Rio de Janeiro: Campus, 1999.

SVEIBY, K.E. O valor do intangível. HSM Management, n.22, p. 66-69, 2000.

STEWART, T. A. Capital intelectual. Rio de Janeiro: Campus, 1998.

ZABOT, J.; SILVA, L. Gestão do conhecimento aprendizagem e tecnologia: construindo a inteligência coletiva. São Paulo: Atlas, 2002. 